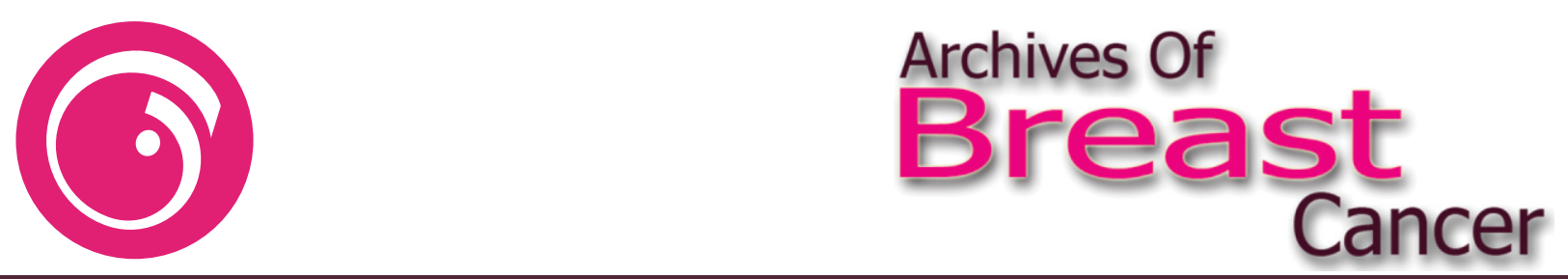

DOI: $10.19187 / a b c .201963100-101$

\title{
Ethical Issues and Palliative Care in Advanced Breast Cancer Patients
}

\author{
Mamak Tahmasebi ${ }^{* a}$ \\ ${ }^{a}$ Gynecologist/Palliative Medicine Fellow, Cancer Institute, Tehran University of Medical Sciences, Tehran, Iran
}

\author{
How people die remains in the memory of those \\ who liveon." \\ Cicely Saunders (1918-2005)
}

Everybody dies; some at home and some in a hospital. Lucky people die in situations where they may receive both physical and emotional care. Endof-life care is a part of palliative care provided in the last days of patients' life to allow them to die with dignity. End-of-life care priorities include communicating about prognosis, discussing the medical futility, assisting with decisions on invasive procedures such as cardiopulmonary resuscitation or mechanical ventilation, and planning for prudent pain and symptom management. While patients are considered the center of the care, their relatives are commonly forgotten. Questions such as what they should be expecting in the next hours or days, or what they should know about dying, death and after, remain unanswered. ${ }^{1}$

Ms. N. was a 73-year-old woman with metastatic breast cancer. She was referred to the palliative clinic in the final days of her life with advanced breast cancer. She was disoriented, experiencing a lot of pain and discomfort along with other complications secondary to brain metastasis. Her children were informed of her prognosis and her comfort was their request. Ms. N. was admitted to the hospice that day and passed away peacefully at 1:00 a.m. next day, surrounded by her five children.

The on-call physician arrived with some delay to sign the death certificate. Having looked through the half-open door of the room and heard the sounds of

\author{
Address for correspondence: \\ Mamak Tahmasebi, MD \\ Associate Professor, \\ Address: Imam Khomeini Hospital, Cancer Institute, Gharib St., \\ 1419733141, Tehran, Iran \\ Tel: +982166581542 \\ Email:mamaktahma@yahoo.com
}

crying, the doctor might have thought that stepping inside may be an unnecessary intrusion into the family's need for privacy. The ambulance crew arrived to transfer the body to the morgue before Ms. N.'s grieving children had finished their mourning rituals.

As the body was being transferred to the morgue by ambulance, the atmosphere completely changed in front of the morgue when one of her sons noticed something; "Look! My mother is alive; she is peeing," he shouted at the driver, and before anybody had time to digest what he had said, he hastily opened up the shroud.

The next few minutes were the most disturbing moments for the family and the staff. At the family's desperate cry, the ambulance staff was coerced to transfer the body to the ED. Ms. N.'s naked body was subjected to resuscitation and given CPR at her children's request.

The moral of the story lies in the stages of grief and the way the medical care providers support the family in these stages. It takes time for close friends and family to pull themselves together after somebody dies. Failing to explain to them what to expect, urging them to quickly transfer the body to the mortuary, or forcing them to mourn in silence or not to complete their ritual can leave them in a state of shock and disbelief. This may result in errors of judgment. Every family has a unique grieving pace and pattern that should be respected by health care providers. The unnecessary hastening of the grieving process will be deemed disrespectful. The delay in the physician's coming to sign the death certificate, in this case, could have been interpreted as "uncaring," further distressing the family.

Proper professional communication with a family who has just lost a beloved one is a very delicate matter. Signing the death certificate is only the technical part of a physician's job. Examining the dead body with respect and empathizing with the family and supporting them would be the fully humane and professional duty of the care provider. ${ }^{2}$ 
Even when a death is expected, coming into terms with death is difficult, especially for close friends and family. Some changes will happen after death, and it is very important to reassure close relatives or friends that these changes are quite normal. The body's sphincters relax and cause the exit of the gas and stool from the rectum, the stomach's secretion from the mouth, or the urine from the bladder. This might be insufferable for those who are not expecting these events. All health care providers should learn about the physical changes after death in addition to receiving bereavement training. ${ }^{2,3}$

The family's response to their loss may be emotional and, possibly, traumatic when the patient has been referred to palliative care services late. Building trust is crucial, as is an understanding of family dynamics. Responding appropriately requires sufficient time. The symptom relief should be started soon, comfort and dignity safeguarded, while the family is being cared for and prepared to lose the loved one. It should be exceptional for referral to a palliative care service in the last few days of life. Offering the best supportive and palliative care should be part of the responsibility of all cancer team members (surgeons, medical oncologists, radiotherapists), in addition to trying hard to control cancer.

Support for the staff and acknowledging how they struggle to deal with a stressful working environment, difficult patients, or their difficult family members are vital. The staff must feel supported and appreciated while they are striving to deliver the best care at the final hours of a dying patient. This experience is moving, valuable, and highly educational for the staff. ${ }^{2}$

End-of-life care refers to providing treatment and care for people who are nearing the end of their life, and support for their family members. End-of-life care is not palliative care but is an important part of it. It goes without saying that caring for dying persons and their families is demanding and very stressful, but when this goes well, it is extremely rewarding!

\section{"The soul has been given its own ears to hear the things the mind doesn 't understand" \\ Rumi}

\section{Aethical Consideration}

For the sake of confidentiality, the names of people and places were removed and are anonymous. Details which could have resulted in the identification of the case were not disclosed.

\section{Conflict of Interest}

None.

\section{References}

1. Kastbom L, Milberg A, Karlsson M. A good death from the perspective of palliative cancer patients.
Support Care Cancer 2017; 25:933.

2. Berry M, Brink E, Harris J, Sleeman KE. Supporting relatives and carers at the end of a patient's life. BMJ 2017; 356:j367.

3. Murray Parkes C. Bereavement in adult life: Coping with loss. BMJ 1998; 316: 856-859. 